\title{
Sustainable Use of Arsenic-Removing Sand Filters in Vietnam: Psychological and Social Factors
}

\author{
Robert Tobias* and Michael Berg \\ Eawag, Swiss Federal Institute of Aquatic Science and Technology, \\ 8600 Dübendorf, $\underline{\text { Switzerland }}$
}

Corresponding author e-mail: Robert.Tobias@eawag.ch; phone: +41-58-765 5432; fax: +41-58-765 5375.

This document is the Accepted Manuscript version of a Published Work that appeared in final form in Environmental Science and Technology, copyright (C) American Chemical Society after peer review and technical editing by the publisher. To access the final edited and published work see http://doi.org/10.1021/es102076x. 


\section{Abstract}

Elevated arsenic concentrations in drinking water pose a health threat to millions of people. Although point-of-use sand filters provide an effective technical solution for mitigating arsenic exposure, the actual reduction in health risk also depends on psychological factors that influence behaviors related to this device. For example, acquiring a sand filter must be preferred to competing options for investing effort and money and, once installed, the users must regularly maintain the filters. These key behaviors of sustainable use are related to psychological factors, such as problem awareness, benefits and costs, social and affective influences, and the perception of practical difficulties. This study investigated the sustainable use of arsenic-removing sand filters in Vietnam. Based on questionnaire surveys, data were gathered in 2007 and analyzed with regression models. Psychological factors explained significant variance in the investigated key behaviors. Significant factors included perceived improvements in water healthiness and taste, monetary costs, social norms, and affective influences. In questions with open answers, interviewees mentioned various practical problems, particularly those related to the inflexibility of the device and the effort of changing the sand. Interestingly, many interviewees operate the sand filters for removing iron from the water but are unaware of problems with arsenic.

Keywords: diffusion of innovations, questionnaires, arsenic contamination, mitigation, arsenic removal, groundwater, drinking water, point-of-use treatment, acceptance

Brief: Questionnaire-based investigation of psychological factors related to the sustainable use of arsenic-removing sand filters in Vietnam. 


\section{Introduction}

For many problematic human-environment interactions, technical solutions are available or in development. However, in many cases, the beneficial effects of technical solutions are only achieved if the devices are actually acquired and properly used by the target population. Compared to the effort invested in the development of technical solutions, relatively little energy is spent to investigate and change individual behaviors. A common misconception is that an innovation will spread by itself if it is sufficiently advantageous. This is often not the case, even when the innovation has direct benefits for individuals (1). An example of this problem is the striking absence of spontaneous diffusion of point-of-use water treatment technologies in developing countries. These technologies combine high benefits with low costs, and yet, in many cases, they still do not diffuse without repeated interventions by promoters (2). The present study takes a close look at the psychological and social factors related to the sustainable use of a device for removing arsenic from drinking water in rural areas of Vietnam $(3,4)$.

\section{Arsenic contamination of drinking water and mitigation by sand filters in Vietnam}

More than 100 million people worldwide ingest excessive amounts of arsenic by consuming groundwater contaminated from natural geogenic sources (5). Many Asian countries, in particular Bangladesh, India, Cambodia, and Vietnam, are known to be affected by high groundwater arsenic concentrations as a result of chemically reducing aquifer conditions. Literature on the arsenic problem in Asia is compiled in the Supporting Information on Pages S2 to S3.

The problem of arsenic intake with contaminated drinking water has emerged over the past three decades. Formerly, drinking water supplies in rural areas consisted mainly of surface water and shallow dug wells. However, due to frequent contamination with fecal pathogens, these sources of water have been largely replaced in Southeast Asia by groundwater pumped through family-owned tubewells, which are generally free of pathogens. However, groundwater in some geochemical settings may contain elevated levels of arsenic. Water containing arsenic concentrations of $\geq 10 \mu \mathrm{g} / \mathrm{L}$ causes chronic health problems if consumed over a period of 5-10 years (6). Long-term (chronic) exposure to arsenic leads to skin pigmentation, hyperkeratosis, cancer, and cardiovascular disease 
and may also affect the mental development of children, among other possible adverse effects $(6,7)$.

Development of the disease is dependent on exposure time and arsenic levels in the body $(8,9)$. The European maximum admissible concentration, the World Health Organization guideline, and the United States maximum contaminant level are all set at $10 \mu \mathrm{g} / \mathrm{L}$. Many developing countries apply $50 \mu \mathrm{g} / \mathrm{L}$ as a threshold. Vietnam lowered its drinking water standard to $10 \mu \mathrm{g} / \mathrm{L}$ in 2002.

Arsenic concentrations in groundwater resources in Vietnam reach levels $>1000 \mu \mathrm{g} / \mathrm{L}$ (3). This serious health threat was identified in 1998 in the Red River Delta of Northern Vietnam (10), where family-based tubewells were introduced in the mid-1990s. The first individuals suffering from arsenic poisoning were identified some 10 years later, in 2004. A comprehensive groundwater survey published in 2011 revealed that $27 \%$ of the wells in the Red River delta exceed the WHO guideline value of $10 \mu \mathrm{g} / \mathrm{L}(11)$. Nevertheless, approaches for arsenic mitigation at the household level face a number of difficulties. An appropriate system for arsenic removal should be efficient, inexpensive, socially acceptable, user-friendly, locally available, and operated without additives. While various approaches for mitigation have been evaluated in Bangladesh (12), sand filters are the main option for arsenic removal in households in rural Vietnam (4).
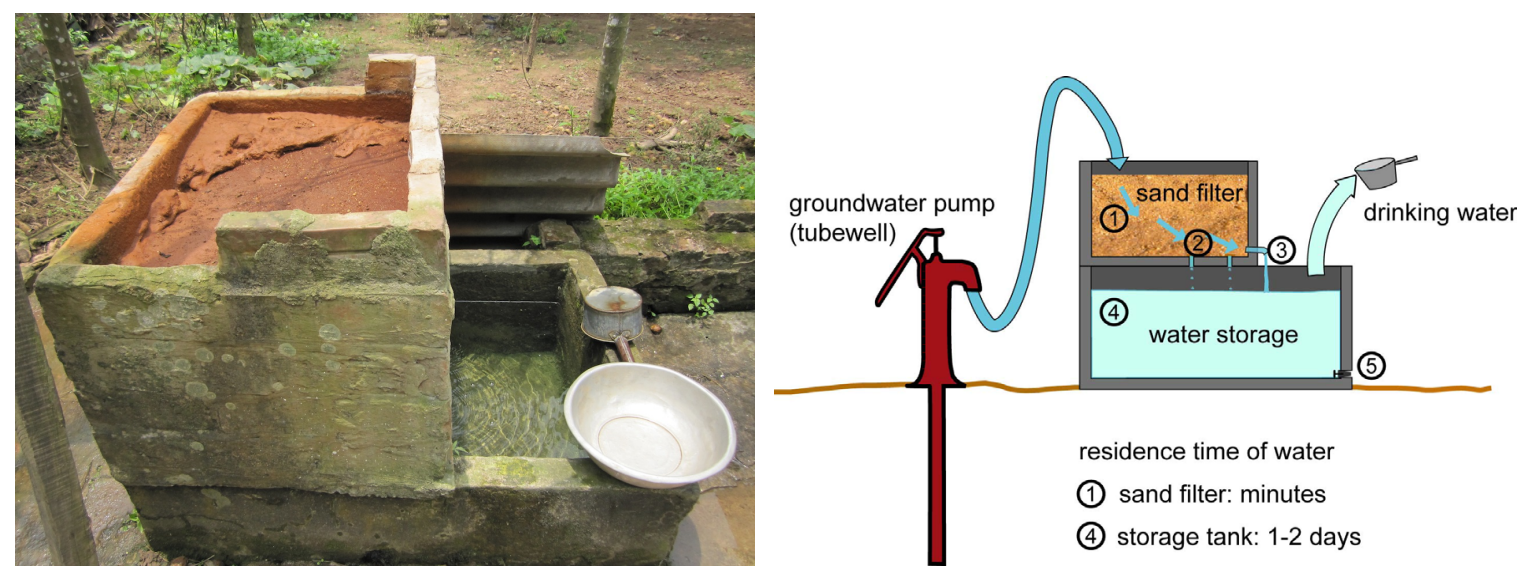

This image by Michael Berg, Eawag

Figure 1. Household sand filter for point-of-use arsenic removal in the backyard of a rural household in Vietnam. Sand filters comprise two superimposed concrete containers. The upper container $(0.05-$ $0.1 \mathrm{~m}^{3}$ ) is filled with locally available sand, while the lower stores the filtered water (4). Groundwater, which is pumped from the tubewell into the upper container, trickles through the sand into the underlying water storage tank $\left(0.2-0.3 \mathrm{~m}^{3}\right)$. Arsenic removal is governed by the precipitation of iron (hydr)oxides on the sand surfaces (note brown coloring). Arsenic then adsorbs to the iron (hydr)oxides and remains immobilized under ambient conditions (13). 
Household sand filters (Figure 1) are simple to operate and remove $80 \%$ of arsenic, on average, from groundwater containing $\geq 1 \mathrm{mg} / \mathrm{L}$ of dissolved iron or an iron/arsenic ratio of $\geq 50$ (4). The operation costs are low and the construction materials are locally available. These filters are operated without chemicals, they can treat a reasonable amount of groundwater within a short time, and they can easily be installed by the affected communities. Elevated concentrations of arsenic in groundwater are often accompanied by high levels of dissolved iron, which can convey a bad taste to the groundwater; in Vietnam, this is described as a "fishy" taste. The visually observable removal of iron from the pumped water makes the effect of sand filters recognizable even to people who are not aware of the arsenic problem. Thus, sand filters are a good option for arsenic mitigation in Vietnam, with a high potential to be successfully applied in other arsenic-affected regions.

Two years after studying the sand filter efficiencies (4), concentrations of arsenic in hair samples of people drinking sand-filtered water or untreated groundwater were compared. The hair analysis showed that the arsenic burden of people drinking sand-filtered water dropped to levels where pathological skin problems should not develop (4). The demonstration of this health benefit was important for wide promotion of sand filters by local authorities.

\section{Key behaviors of sustainable use and related psychological factors}

Sustainable use of a technical innovation is much more than a simple one-time decision to acquire the device (1). In order for household members to sustainably use arsenic-removing sand filters, they must demonstrate a set of interrelated key behaviors: they must decide to choose a sand filter instead of other alternatives for investing effort and money, and they must acquire, use, and maintain the sand filter properly.

1. Decision (relative priority given to sand filters in relation to other potential purchases or expenditures): Does a household prefer to invest its limited resources (e.g., time, money) in acquiring a sand filter or rather opt for a competing option like buying a motorbike or constructing another room for their house?

2. Acquisition (investment of resources to get a sand filter): Do the households implement their decision by building or buying (i.e., hiring professionals to build) sand filters? Here, any 
household that has a sand filter is classified as having acquired one, since no sand filters in the investigated area were built or financed by any external organizations.

3. Use (regular and proper application of the device): Do all members of a household only consume water treated by the sand filter? Since all households with a sand filter only consumed treated water, use was not analyzed.

4. Maintenance (continuous small investments of resources to keep the sand filter functional): Do the households change or wash the sand of the filters at intervals of about once every three months to maintain the arsenic-removal effective?

Each of these key behaviors depends on a number of psychological factors that can be derived from theory:

1. Costs and benefits of the innovation: Economic rational-choice theories (e.g., 14) state that behavioral decisions are determined by the subjective evaluation of the costs and benefits of performing the behavior. Here, benefits regarding health and taste and the costs in terms of money, time, and physical effort are of particular interest. Further, it must be considered how important these benefits and costs are for the persons.

2. User attitudes: Attitude research (15) distinguishes the instrumental attitude from the affective attitude. The former refers to balancing costs and benefits of a behavior as just explained. The latter refers to affective (emotional) influences like, for example, whether a behavior is perceived as enjoyable or displeasing, or whether a person feels committed to perform the behavior. A committed person feels an emotional involvement to perform the behavior, feels confidence and has positive feelings in respect of a future performance of the behavior and negative feelings in case of not having performed the behavior (e.g., if it was forgotten).

3. Social norms: Two general classes of social influences are often distinguished (16): the descriptive norm represents what the interviewees think is usually done (i.e., what they think others are doing), while the injunctive norm represents what the interviewees think is correct to do (i.e., whether others would think good or bad about them if they perform the behavior).

4. Perceived difficulty: Besides attitudes and social norms, the Theory of Planned Behavior (17) mentions the perceived difficulty of performing a behavior as determinant of behaviors. 
Besides the general assessment of the difficulty, also specific practical problems related to acquiring, using, and maintaining a sand filter are of interest.

5. Knowledge and memory: A number of psychological models consider also knowledge as important determinant of behaviors (e.g., 19). Here, critical knowledge comprises information about problems related to contaminated water, in particular about arsenic, and about measures to mitigate these problems. We do not distinguish between knowledge that was never acquired and knowledge that was forgotten. That is why we group together knowledge and memory. However, not only knowledge can be forgotten but the behavior performance itself (20). This is particularly critical for repeated behaviors as, for example, the maintenance of the sand filters. On the other hand, it is also of interest why such a behavior is not forgotten (i.e., what reminds the persons to perform it).

Not all factors are expected to influence all key behaviors of sustainable use in the same way and there might be considerable differences depending on the innovation and the target population (21, 22). The present study sheds light on the effects of psychological factors on the sustainable use of arsenic-removing sand filters in Vietnam by targeting two questions: (1) To what extent do the different psychological factors explain the different key behaviors of sustainable use, and (2) what can be done to promote the sustainable use of sand filters in Vietnam?

\section{Materials and Methods}

Data were gathered by face-to-face interviews in spring 2007. The questionnaires were developed in close interchange with Vietnamese scientists and students from CETASD (Centre of Environmental Technology and Sustainable Development, Hanoi University of Science). The survey was carried out in four villages in the former province of Ha Tay, near Hanoi, by members of the CETASD. The villages were selected according to a high mean arsenic concentration in the ground water and the number of sand filters in the village. The aim was to have about the same number of households with and without sand filters. Within these villages, the sample was drawn using a Random-Route procedure: the interviewers started from the center of the villages in each direction and surveyed every second household. The interviewees were informed that participation in the 
survey was completely voluntary, but none of the persons asked declined to be interviewed. We are confident that the sample is representative of the villages. However, due to the vicinity to the capital city of Hanoi, these villages may not be representative of the more remote rural areas of Vietnam.

The design of the questionnaires and items is described in the Supporting Information on Pages S4 to S6. The questionnaires contained a mixture of open and closed questions for measuring psychological factors related to the different key behaviors identified above. Specific questions were designed to quantify user perceptions regarding benefits and costs, difficulties and problems, knowledge and forgetting, affective and normative evaluations, social networks, and details on decision-making and acquisition. Since a behavior cannot be evaluated in isolation, the interviewees were also asked what purchase or activity they might do instead of buying or building a sand filter. This competing behavior was then investigated in the same way as the target behavior (i.e., acquiring and maintaining a sand filter). Data were analyzed with binomial logistic and linear regression models in SPSS 17. Details on the procedure can be found in the Supporting Information on Page S9.

\section{Results}

\section{Descriptive results of key behaviors}

In total, data from 319 households were gathered. Of these, 162 had an arsenic-removing sand filter and 157 did not. Figure $2 \mathrm{a}$ shows the filter distribution over the investigated households in the four villages. It is striking that in some villages almost everybody uses a sand filter while other villages just have few users. 


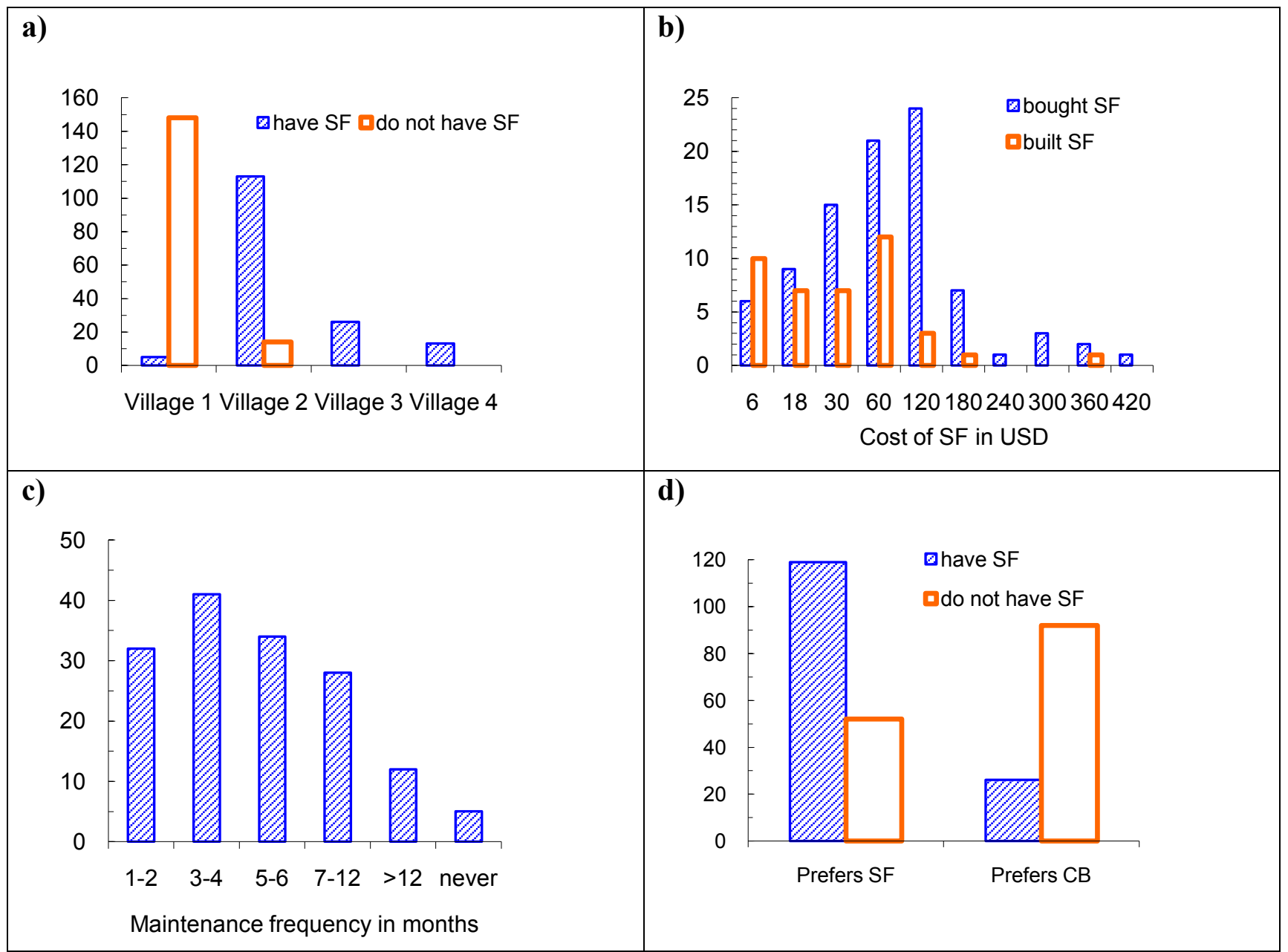

Figure 2. Distributions of frequencies. a) Frequency of interviewed households with and without sand filters $(S F)$ in the villages investigated. b) Frequencies of the cost of the sand filter in USD for households that bought or built a sand filter $(S F)$. c) Frequencies of how often the sand of the filters is changed or washed ( $m=$ months). d) Frequencies of preference of obtaining a sand filter $(S F)$ or performing the competing behavior $(C B)$ for households with and without sand filters.

Having a sand filter was strongly related to having a groundwater tubewell: In Village 1, which had few sand filters, only 14 out of 153 households drew drinking water from tubewells, while in the other three villages, 119 out of 166 households did so. Respondents frequently noted that tubewells are usually sold as a package together with sand filters.

All households that have a sand filter reported spending at least 0.1 million VND (6 USD) for it. Most households spent less than 3 million VND (180 USD). Households that built the sand filter themselves usually paid less than households that paid professionals to build one (Figure 2b). As a reference for the value of these numbers, the households were asked how much money they could save per month: $36 \%$ answered less than 0.2 million VND (12 USD), $27 \% 0.2$ to 0.5 million VND (12 - 30 USD), $23 \% 0.5$ to 1 million VND (30 - 60 USD), and $14 \%$ more than 1 million VND. 
On average, respondents reported changing sand in the filters every three to four months (Figure 2c). This is near the recommended frequency of changing the sand every three months. However, $52 \%$ of the households changed it less frequently.

Figure $2 \mathrm{~d}$ shows the preferences of households with and without sand filters. Eighty-two percent of the respondents with sand filters would decide again in favor of it. Among households without sand filters, 36\% still decided in favor of sand filters. Thus, a substantial proportion of respondents without sand filters would prefer to have one. Competing behaviors mentioned by the interviewees included other construction projects like building a toilet or a new room (45\%), buying appliances or furniture (26\%), buying vehicles, particularly motorbikes, $(11 \%)$, acquiring other water treatment devices $(6 \%)$, using the money for business $(6 \%)$, or giving it to their children $(5 \%)$.

\section{Descriptive results of psychological factors}

Besides taste (important or very important for $70 \%$ of the interviewees), the perceived health effect of the sand filters was one of the most important benefits mentioned and health issues were seen as important or very important by $76 \%$ of the interviewees. However, they did not know much about the arsenic problem and knowledge about this issue did not correlate with any of the key behaviors. Instead, the interviewees mentioned a wide range of contaminations that the sand filters eliminate (e.g., iron, lime, salt, manganese, bacteria, etc.) or health problems that they reduce (indigestion, allergies, kidney stones, cancer, reduced intelligence, etc.). An unexpected advantage of sand filters was mentioned in open-ended questions by $48 \%$ of all interviewees: the sand filters clean a large amount of water, not only for drinking but also for bathing, doing laundry, and other purposes. In fact, the sand filters seem to be installed primarily for removing the iron dissolved in the groundwater and not for removing arsenic.

The most important problems with the sand filters mentioned in open-ended questions were the inflexibility of the device (49 mentions of problems with space requirement, weight, or immobility) and practical problems (35 mentions of problems with pumping, like power outages, slow water drainage, or lack of knowledge of how to repair the filters). Practical problems with maintenance (particularly getting the used sand out and lifting the new sand up, often to some height, to the 
installed filters) were mentioned 31 times. Forgetting the maintenance does not seem to be a problem, since a reduction of the usually high water flow (61 of 157 mentions) and the change in color and taste (37 mentions) act as natural reminders. Since only for the latter a closed question was included in the questionnaire, we used the time until the appearance of water color changes as an indicator of remembering in our regression analyses.

\section{Regression results}

The regression models were able to explain a high proportion of observed variance $\left(\mathrm{R}^{2}=70 \%\right.$ for decision, $79 \%$ for acquisition, and 53\% for maintenance), showing that key behaviors of sustainable use are strongly related to psychological factors and that the survey captured the most important of these factors. The results of the regression analyses on the three key behaviors investigated (decision, acquisition, and maintenance) are illustrated in Figure 3. More details can be found in Table S4 of the Supporting Information. Figure 3 shows which psychological factors and more specifically which survey questions are significantly related to the key behaviors. Further, the directions of the relations (i.e., whether an increase of the values of a psychological factor increases or decreases a key behavior) and the uncertainties of the estimates (i.e., the $95 \%$ confidence intervals) are presented. The sizes of the effects (i.e. the lengths of the bars in Figure 3) cannot be compared directly, since they depend on the ranges and units of the variables. These results are explained in the following sections. 


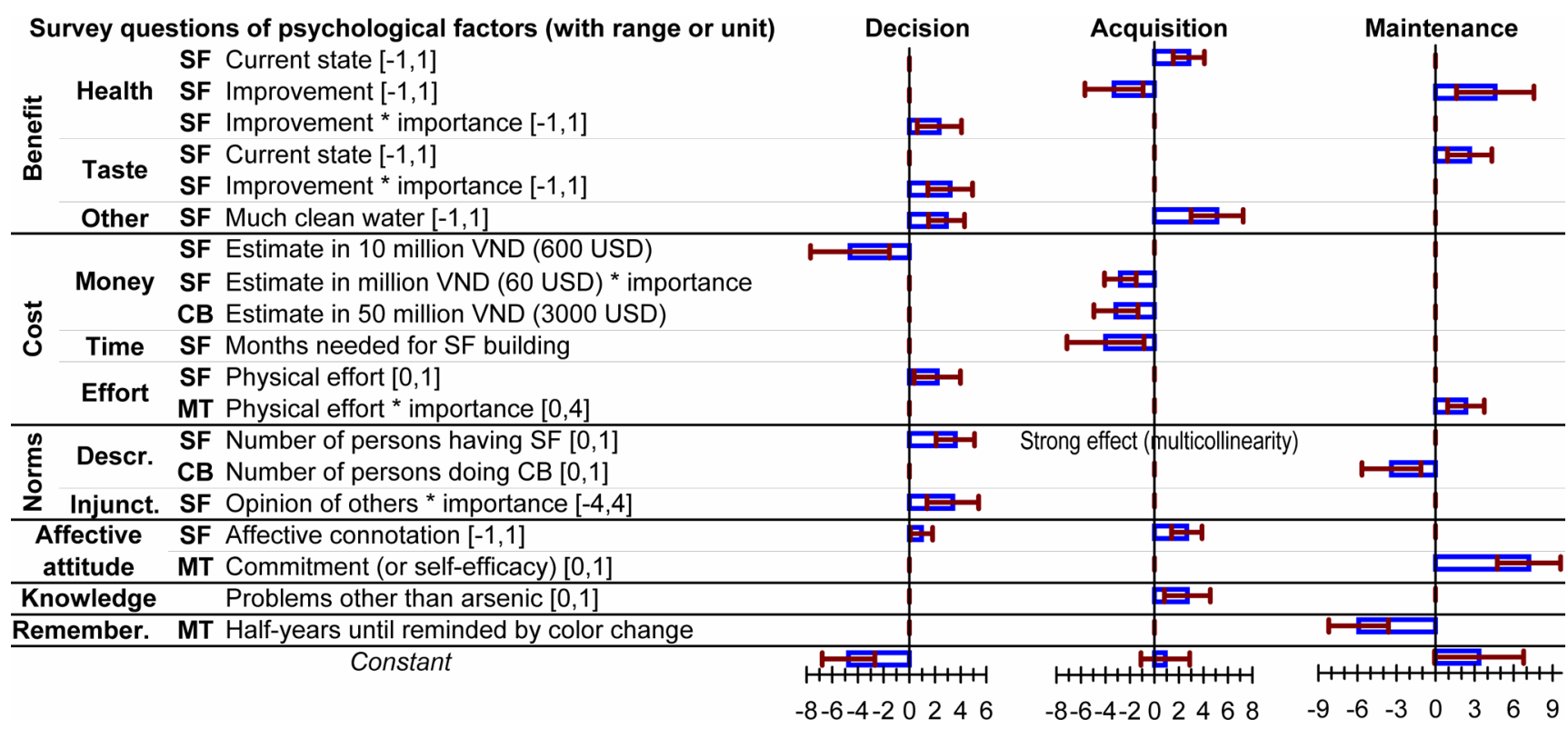

Figure 3. Results of regression analyses for explaining key behaviors of sustainable use, illustrated as non-standardized parameters of the regression equation and their $95 \%$ confidence intervals. The dependent variables are Decision (prefers $\mathrm{CB}=0$ or $\mathrm{SF}=1$ ), Acquisition (household without $\mathrm{SF}=0$ or with $\mathrm{SF}=1)$, and Maintenance $(1 /$ maintenance frequency in days). $\mathrm{SF}=$ sand filter, $\mathrm{CB}=$ competing behavior, $\mathrm{MT}=$ maintenance, $\mathrm{VND}=$ Vietnam Dong (about 6E-5 USD). * importance $=$ variable is weighted by importance (i.e., the data of this survey question was multiplied by data of another survey question that asked about the importance of what was asked in the first question).

\section{Benefits}

User perceptions of positive health effects ("Do you think your drinking-water would / has become more or less healthy if you had / because you have a sand-filter?") are related to all three key behaviors. For the decision, this relation depends on the importance of health issues. For acquisition, the relationship is negative. This counterintuitive result can be explained by considering a second significant relation of health effects on acquisition: the current state of the water ("How healthy do you think is your drinking-water?") is positively related to acquisition. Thus, persons who have a sand filter consider their water (coming from the sand filter) as healthier than that of persons without filters. Conversely, those without filters expect a large improvement in the healthiness of their water if they were to install a filter. Thus, the perceived effect of the sand filter on the healthiness of the water is a critical attribute for the sustainable use of this innovation - even without knowledge of arsenic-related problems.

Another important benefit of sand filters is the improvement in the taste of the water. For the decision, the improvement in taste due to the sand filter ("Do you think the taste of your drinking- 
water would / has become better or worse if / since you built the sand-filter?") is crucial, while for maintenance, the current taste of the water ("How does your drinking-water taste at the moment?") is more important. Thus, people who maintain their filter more often feel that their water tastes better. No significant effect of taste was found on acquisition of sand filters.

A third benefit of having a sand filter was mentioned in the open-ended questions on advantages and disadvantages: the availability of large quantities of clean water (e.g., for washing, laundry, etc.). This advantage has significant effects on the decision and the acquisition of sand filters. No effect was seen for maintenance, which does not increase the amount of water available for use.

\section{Costs}

Monetary costs ("How much money would / did it cost to build a sand-filter?") have negative effects on the decision and the acquisition of sand filters. Surprisingly, the costs for the competing behavior ("How much money would it cost to do the competing behavior?") are negatively related to the acquisition of the filters. Based on the pattern of correlations, this result can be ascribed to the form the households decide on acquisitions. Considering all data, the cost for the competing behavior has a correlation with acquisition of $r=-0.20$. Calculating the correlation only for poor households (i.e., households that can save less than 500,000 VND, about $30 \mathrm{USD}$, per month), it increases to $\mathrm{r}=$ -0.28 , while for richer households alone (i.e., households that can save more than 500,000 VND), no significant correlation can be found. Therefore, it seems that the households do not select between sand filters and the competing behavior but perform the latter anyway and decide whether the sand filter can be acquired additionally to the competing behavior. If the households have enough money, the cost of the competing behavior does not influence the decision to acquire a sand filter. If the money is sparse, the competing behavior might make it difficult to acquire a sand filter.

Some households decided to build the sand filter on their own, requiring time and physical effort. As expected, the time needed to build a filter ("How much time would / did it take to build a sandfilter, including constructing and organizing materials and help from others?") has a negative effect on acquisition (none on decision or maintenance). Surprisingly, however, the physical effort necessary to build a filter ("How much physical effort would / did it take to build a sand-filter?") is positively related to the decision (no effect on acquisition or maintenance). This can be explained by 
the different importance of monetary costs and physical effort: While $40 \%$ of the interviewees rate monetary costs as important or very important, only $17 \%$ rate investments of time or physical effort as important or very important. Thus, people who build the sand filters themselves have to expend more effort, but less money, which makes the filters appear less expensive. Physical effort for maintenance (“How much physical effort does it take to wash or change the sand?") is also positively related to maintenance. Here, the costs are directly related to the behavior frequency: The more often the sand is changed, the more physical effort has to be invested over time.

\section{Social influences}

Social influences turned out to be significant for all three key behaviors. The descriptive norm for having sand filters ("How many of your neighbors and friends have a sand-filter or are building one at the moment?") is strongly related to decision and acquisition. The correlation for the latter is so strong $(r=0.87)$ that, due to multicollinearity, the variable could not be included in the regression analysis. Maintenance is not related to descriptive norms regarding the sand filter, but (negatively) to the descriptive norm of performing the competing behavior ("How many of your neighbors and friends are doing $\mathrm{CB}$ or are about to do it?"). Thus, the more persons perform the competing behavior, the lower the maintenance frequency. The injunctive norm of having a sand filter ("Do you think people would think / have thought better or worse of you if / since you built the sand-filter?") is only related to decision.

\section{Affective influences, difficulties, knowledge, and memory}

Affective influences are important for all three key behaviors. Decision and acquisition are related to the affective connotation of building sand filters ("Do you think building a sand-filter is enjoyable for you?"). Maintenance is related to the indicator for being committed to perform maintenance within 3 months ("Will you change or wash the sand of your sand-filter in the next 3 months?"). As explained in the introduction, commitment is understood as an emotional involvement to perform the behavior. However, how sure somebody is that he or she will perform a behavior might also be interpreted as an indicator for self-efficacy (i.e., how confident a person feels able to perform a behavior; e.g., 23). In any case, this variable is an important predictor for maintenance. 
In the regression analyses, none of the survey questions regarding the difficulty of performing the behaviors had significant effects. Knowledge about water-related problems other than arsenic ("Do you think you can drink your groundwater without treatment or do you know of problems with the water?") is related to acquisition, but not the other two key behaviors. Knowledge about arsenicrelated problems did not correlate with any key behavior, perhaps because only $12 \%$ of respondents had any knowledge about such problems. Regarding maintenance, forgetting seems not to be an issue, because of natural reminders - in this case, the color of the water is used as indicator ("Does the color of the sand in the sand-filter change over time without changing or washing it? How long does it take until you notice it?").

\section{Discussion}

The regression analyses show that sustainable use of sand filters depends strongly on psychological factors. This reconfirms findings related to the use of other devices such as, for example, arsenic-safe deep-tubewells $(21)$ or solar water disinfection $(18,24)$. In contrast to existing research, this study shows that the different key behaviors of sustainable use depend on different psychological factors. Thus, the investigation of the use of technical devices requires a broad assessment of the psychological and social situation and must explicitly address the different key behaviors of sustainable use.

Advantages and disadvantages are important in the case of the sustainable use of sand filters, as stated by the economic rational-choice theories (e.g., 14). The main perceived advantages of sand filters are the improvements in healthiness and taste of the water. This is typical for point-of-use water treatment techniques (e.g., 24). However, sand filters have the additional advantage of treating large quantities of water, which then also can be used for washing, doing laundry, etc. In contrast to many studies on the acceptance of point-of-use water treatment techniques (e.g., 18), monetary costs for acquiring sand filters, as well as physical effort for maintenance, turned out to be important. This difference can be attributed to the fact that most investigations on the use of similar water treatment technologies are done in the context of development-aid campaigns, in which the treatment technology is highly subsidized or provided for free. The investigation further indicates that the 
households do not abstain from competing behaviors in order to acquire a sand filter. If they can afford both, they acquire a sand filter; if not, only the competing behavior is implemented.

In addition to benefits and costs, other psychological factors were significant for all three key behaviors. As psychological theories on behavior selection propose (e.g., the Theory of Planned Behavior, 17), social and affective influences are critical. In particular, the descriptive norms (i.e., what people think, how many other persons perform a certain behavior) are very influential. This has been observed in many studies in developing countries (e.g., 18). Also typical for point-of-use water treatment techniques (e.g., 24, 18), the affective connotation of the behavior is essential. Particularly important is the confidence of the persons that they will perform the maintenance. As explained, this can be interpreted as a feeling of commitment (i.e., an emotional involvement to perform the behavior) or an aspect of self-efficacy (i.e., the assessment of how much one feels able to perform the behavior). Again, similar evidence was found in other studies (e.g., 21).

None of the questions assessing the difficulties of performing the behaviors significantly improved the regression models. However, in open-ended questions, the interviewees mentioned a wide range of problems in performing the investigated behaviors. The inflexibility of the filters in the case of rebuilding parts of the house, and changing the sand of filters, which are installed at some height, were mentioned frequently. Therefore, even if no significant relationships resulted, possible practical problems should be considered when promoting sand filters.

Knowledge is mainly considered in stage models of behavioral change (e.g., 1, 19). These models assume that a person must first know and understand the innovation and the problems it solves. The person then develops a preference and comes to a decision. The present results show that a critical knowledge regarding arsenic contamination of drinking water is not necessary for the sustainable use of sand filters. The reason for this is that the sand filters have additional advantages like removing iron from the water. In fact, knowledge about other water-related problems is related to acquisition. Obviously, not in all cases such 'secondary advantages' exist. But whenever promoting technical innovations, it is worth while searching for advantages that are easy to understand and important to the target population, even if these advantages are not the primary objective of the technology to be introduced. Memory processes (i.e., forgetting to perform a behavior) are of particular relevance in 
the case of repeated behaviors (20). Even though forgetting is not a problem for the behaviors under investigation, the important role of being reminded to perform the maintenance confirms the importance of memory processes.

This overview shows that sustainable use of arsenic-removing sand filters can be adequately explained using traditional psychological concepts and theories. Therefore, well-investigated psychological techniques for influencing the critical factors (22) could be applied for promoting sustainable use.

\section{Implications for practice}

Sand filters seem to be well established in the investigated region, possibly due to a commercial coupling of the construction of sand filters with tubewell installation. However, many households are still in need of an arsenic-removing filter or have to improve maintenance practices. To reach these goals and also to promote sand filters in regions where the technology is not as established, the following issues should be considered:

1. The regression analyses showed an important influence of cost and benefit considerations on acquisition and maintenance of sand filters. Thus, a promotion campaign can build on this and emphasize the advantages of improved healthiness and taste, as well as the availability of large quantities of clean water for washing, laundry, etc. On the other hand, the monetary costs are already critical for the relatively rich population investigated in this study and therefore might be a problem in more rural areas. An approach to overcome these problems is to persuade the people and to help them plan the purchase of different goods so that sand filters are no longer only considered if there is still money left after purchasing other goods.

2. The analyses showed that social norms are very influential. Thus, the idea must be promoted that it is desirable and common to have, use, and maintain sand filters.

3. Affective influences turned out to be another important factor in the regression analyses. Changing the affective connotation of building sand filters might be difficult. However, the important role of the commitment for maintenance can be used, for example, by letting the filter users commit themselves more formally and/or publicly to perform the maintenance every three months. 
4. As presented in the descriptive results, the users of sand filters struggle with some practical difficulties due to the inflexibility of the device and with changing the sand. These problems could be eased with a good planning before building the filter, which takes into consideration possible future changes of the house and facilitates replacing the sand of the filter.

5. Another descriptive result is that the population has little knowledge regarding the problem of elevated arsenic in groundwater. Even though knowledge of this issue does not seem necessary for people to acquire and maintain sand filters, promotion might be facilitated and maintenance increased if the people were aware of the concentration of arsenic in their water, the health problems related to arsenic exposure, and techniques to remove arsenic from the drinking water.

As diffusion agents, the tubewell constructors appear to be particularly promising. They turned out to be surprisingly good at rating water quality and the need for a sand filter after installing a tubewell. Thus, teaching tubewell constructors the points above is suggested as a way to promote the use of sand filters.

This investigation showed the necessity of investigating psychological and social factors related to the sustainable use of a technical innovation that is to be promoted. Sustainable use consists of at least four key behaviors: decision, acquisition, use (not investigated here), and maintenance. Each of these key behaviors is related to different psychological factors: the advantages and disadvantages of the innovation, emotions and norms related to the innovation, practical difficulties, knowledge about the innovation and the problems it solves, and remembering to perform repeated behaviors. Based on this information, campaigns can be designed to promote the innovation (e.g., 22).

It is a large step from identifying environmental problems to producing technical solutions that solve these problems. Nevertheless, obtaining the desired results requires another large step: the development of effective promotion strategies. To accomplish this, the social and psychological barriers of adopting the technical innovation must be identified and, based on this, behavior-change campaigns have to be designed and implemented. Thus, social scientific research should be seen as an essential part of solving environmental problems. 


\section{Acknowledgment}

The project was initiated by Hans-Joachim Mosler (Eawag) and funded by Eawag. Data were gathered by Christian Würzebesser (Eawag), Fabienne Brigger, and Rahel Pfiffner (University of Zurich), and Pham Thi Kim Trang, Vi Mai Lan, and students from CETASD (Vietnam). We thank Stephan Hug, Rick Johnston, Judit Lienert, Hans-Joachim Mosler, Linda Roberts, and Antje Wegner for helpful comments on the manuscript.

\section{Supporting Information Available}

Compilation of literature to the arsenic problem in Asia (pp S2 to S3); questionnaires (pp S4 to S6); descriptive statistics (pp S7 to S8); information on and results of regression analyses (pp S9 to S10). This information is available free of charge via the Internet at http://pubs.acs.org.

\section{Literature Cited}

(1) Rogers, M. E. Diffusion of innovations, 5th ed.; Free Press: New York, USA, 2003.

(2) Tamas, A.; Tobias, R.; Mosler, H.-J. Promotion of solar water disinfection: Comparing the effectiveness of different strategies in a longitudinal field study in Bolivia. Health Commun., 2009, 24, 711-722.

(3) Berg, M.; Tran, H. C.; Nguyen, T. C.; Pham, H. V.; Schertenleib, R.; Giger, W. Arsenic contamination of groundwater and drinking water in Vietnam: A human health threat. Environ. Sci. Technol. 2001, 35, 2621-2626.

(4) Berg, M.; Luzi, S.; Trang, P. T. K.; Viet, P. H.; Giger, W.; Stuben, D. Arsenic removal from groundwater by household sand filters: Comparative field study, model calculations, and health benefits. Environ. Sci. Technol. 2006, 40, 5567-5573.

(5) Amini, M.; Abbaspour, K. C.; Berg, M.; Winkel, L.; Hug, S. J.; Hoehn, E.; Yang, H.; Johnson, C. A. Statistical modeling of global geogenic arsenic contamination in groundwater. Environ. Sci. Technol. 2008, 42, 3669-3675.

(6) Smith, A. H.; Lingas, E. O.; Rahman, M. Contamination of drinking water by arsenic in Bangladesh: a public health emergency. Bull. World Health Org. 2000, 78, 1093-1102.

(7) Wasserman, G. A.; Liu, X. H.; Parvez, F.; Ahsan, H.; Factor-Litvak, P.; van Geen, A.; Slavkovich, V.; Lolacono, N. J.; Cheng, Z. Q.; Hussain, L.; Momotaj, H.; Graziano, J. H. Water arsenic exposure and children's intellectual function in Araihazar, Bangladesh. Environ. Health Persp. 2004, 112, 1329-1333.

(8) Hughes, M. F. Arsenic toxicity and potential mechanisms of action. Toxicol. Lett. 2002, 133, $1-16$.

(9) Yoshida, T.; Yamauchi, H.; Sun, G. F. Chronic health effects in people exposed to arsenic via the drinking water: dose-response relationships in review. Toxicol. Appl. Pharm. 2004, 198, $243-252$. 
(10) Berg, M.; Trang, P. T. K.; Stengel, C.; Buschmann, J.; Viet, P. H.; Dan, N. V.; Giger, W.; Stuben, D. Hydrological and sedimentary controls leading to arsenic contamination of groundwater in the Hanoi area, Vietnam: The impact of iron-arsenic ratios, peat, river bank deposits, and excessive groundwater abstraction. Chem. Geol. 2008, 249, 91-112.

(11) Winkel, L. H. E.; Trang, P. T. K.; Lan, V. M.; Stengel, C.; Amini, M.; Ha, N. T.; Viet, P. H.; Berg, M. Arsenic pollution of groundwater in Vietnam exacerbated by deep aquifer exploitation for more than a century. P. Natl. Acad. Sci. USA 2011, 108, 1246-1251; DOI 10.1073/pnas.1011915108.

(12) Ahmed, M. F.; Ahuja, S.; Alauddin, M.; Hug, S. J.; Lloyd, J. R.; Pfaff, A.; Pichler, T.; Saltikov, C.; Stute, M.; van Geen, A. Ensuring Safe Drinking Water in Bangladesh. Science 2006, 314, 1687-1688.

(13) Hug, S. J.; Leupin, O. X.; Berg, M. Bangladesh and Vietnam: Different groundwater compositions require different approaches to arsenic mitigation. Environ. Sci. Technol. 2008, $42,6318-6323$.

(14) Kahnemann, D.; Tversky, A. Prospect Theory: An analysis of decision under risk. Econometrica, 1979, 47, 263-291.

(15) Breckler, S. J.; Wiggins, E. C. Affect versus evaluation in the structure of attitudes. J. Exp. Soc. Psychol., 1989, 25, 253-271.

(16) Cialdini, R. B.; Reno, R. R.; Kallgren, C. A. A focus theory of normative conduct: Recycling the concept of norms to reduce littering in public places. J. Pers. Soc. Psychol., 1990, 58, $1015-1026$.

(17) Ajzen, I. The theory of planned behavior. Organ. Behav. Hum. Decis. Process., 1991, 50, $179-211$.

(18) Heri, S.; Mosler, H.-J. Factors Affecting the Diffusion of Solar Water Disinfection: A Field Study in Bolivia. Health Educ. Behav., 2008, 35, 541-560.

(19) Schwarzer, R. Modeling health behavior change: How to predict and modify the adoption and maintenance of health behaviors. Appl. Psychol. - Int. Rev., 2008, 57, 1-29.

(20) Tobias, R. Changing behavior by memory aids: a social-psychological model of prospective memory and habit development tested with dynamic field data. Psychol. Rev., 2009, 116, 408-438.

(21) Mosler, H.-J.; Blöchliger, O. R.; Inauen, J. Personal, social, and situational factors influencing the consumption of drinking water from arsenic-safe deep tubewells in Bangladesh. J Environ. Manage., 2010, 91, 1316-1323.

(22) Tobias, R.; Bruegger, A.; Mosler, H.-J. Developing strategies for waste reduction by means of tailored interventions in Santiago de Cuba. Environ. Behav., 2009, 41, 836-865.

(23) Bandura, A. Self-efficacy: toward a unifying theory of behaviour change. Psychol. Rev., 1977, 84, 191-215.

(24) Kraemer, S.M.; Mosler, H.-J. Persuasion factors influencing the decision to use sustainable household water treatment. Int. J. Environ. Heal. R., 2010, 20, 61-79. 